\section{Enzymhalbwertszeiten im Blutkreislauf}

\author{
A. M. Gressner ${ }^{1}$ und O. A. Gressner ${ }^{2}$ \\ ${ }^{1}$ Labor Dr. Wisplinghoff Berlin, Berlin, Deutschland \\ ${ }^{2}$ Labor Dr.Wisplinghoff Köln, Köln, Deutschland
}

Synonym(e) Halbwertszeiten von Enzymen

Englischer Begriff half-life time of enzymes in the circulation

Definition $>$ Halbwertszeiten der Enzyme in der Zirkulation beschreiben die Zeitspanne, die vergeht, um 50 \% der Enzymaktivität aus der Zirkulation zu eliminieren.

Beschreibung Bei Austritt von intrazellulären Enzymen in den Extrazellulärraum kommt es zu zwei, zeitlich abgesetzten Veränderungen der Enzymaktivität:

- Soforteffekt, der in einer Verminderung oder Zunahme der Enzymaktivität aufgrund der Veränderung des Enzymmoleküls in einem fremden Milieu sowie auf eine Verteilung des Enzyms auf den gesamten Extrazellulärraum (intravasal, interstitiell, lymphatisch) zurückzuführen ist. Im Allgemeinen führt der Soforteffekt zu einem primären, schnellen Abfall der Enzymaktivität.

- Phase der Enzymelimination, die eine langsame Abnahme der Enzymaktivität im Plasma darstellt, wobei die Eliminationsgeschwindigkeit unabhängig vom absoluten Wert der Enzymaktivität ist und einer Exponentialfunktion folgt. Die Halbwertszeiten im Plasma sind spezifische Merkmale der jeweiligen Enzyme (s. Tabelle). Spezielle Eliminationsorgane gibt es nicht, jedoch haben Leber, Niere, Lungen und Gastrointestinaltrakt entscheidende Bedeutung. Hervorzuheben ist die weitgehende Konstanz der Eliminationsgeschwindigkeit auch unter pathologi- schen Bedingungen, was bedeutet, dass die Enzymaktivität im Blut unter Krankheitsbedingungen maßgeblich vom Einstrom und weniger von der Eliminationsrate beeinflusst wird. Dies stellt eine wesentliche Grundlage der labormedizinischen Enzymdiagnostik und klinischen Enzymologie dar.

Halbwertszeiten (Mittelwerte) von Enzymen im Blutkreislauf (Angaben entsprechen tierexperimentellen Befunden):

\begin{tabular}{l|l}
\hline Enzym & Halbwertszeit (h) \\
\hline Alanin-Aminotransaminase (ALT, GPT) & 47 \\
\hline Aldolase & 21 \\
\hline Alkalische Phosphatase (AP) & 144 \\
Leber-AP & 52 \\
Plazenta-AP & 168 \\
Knochen-AP & 168 \\
\hline Amylase & $3-6$ \\
\hline Aspartat-Aminotransaminase (AST, GOT) & 17 \\
\hline Creatinkinase (CK) & 15 \\
CK-MM & 17 \\
CK-MB & 12 \\
CK-BB & 5 \\
\hline$\gamma$-Glutamyltransferase $(\gamma-G T)$ & $72-96$ \\
\hline Glutamat-Dehydrogenase (GLDH) & 18 \\
\hline Laktat-Dehydrogenase (LDH) & 116 \\
LDH1 ( $\alpha$-HBDH) & 113 \\
LDH5 & 10 \\
\hline Leuzin-Arylamidase (LAP) & 209 \\
\hline Lipase & $3-6$ \\
\hline Malatdehydrogenase (MDH) & 16 \\
\hline Pseudocholinesterase (PCHE) & 240 \\
\hline Saure Phosphatase (SP) & 4 \\
\hline
\end{tabular}

\section{Literatur}

Schmidt E, Schmidt FW (1981) Kleine Enzym-Fibel. Boehringer $\mathrm{GmbH}$, Mannheim

Wissenschaftliche Tabellen Geigy (1979), 8. Aufl. Ciba-Geigy, Basel 